\title{
Secondary School Fee Inflation: An Analysis of Private High Schools in Victoria, Australia.
}

\author{
Jenny Lye and Joe Hirschberg ${ }^{1}$
}

\begin{abstract}
Over the past decade the private high school sector has been growing in many developed nations. In Australia this sector has grown faster than in any other OECD nation. This has occurred while Australian private secondary school tuition fees have been increasing at a rate that is double the overall rate of inflation. However, this increase has been uneven across different school types. Specifically we find that quality has fallen in the private schools that cater to students from lower socioeconomic homes and that the rate of increase in fees for these schools appears to follow the business cycle.
\end{abstract}

Key words: Catholic Schools, Charter Schools, Hedonic Price Models, Price Indices

7,325 words

1 Department of Economics, University of Melbourne 


\section{Introduction}

Over the last 20 years there has been a notable shift in enrolment towards private secondary schools in many developed nations. Among these nations, Australia has one of the largest private school sectors with approximately $40 \%$ of secondary students enrolled in 2013. By comparison, the OECD average for secondary students enrolled in private schools is closer to $14 \%$ (see Table C1.4 in OECD 2014). Furthermore, from 2000 to 2012 the percent of Australian upper secondary school children in non-public schools has risen by more than in any other OECD nation as can be compared using Figure 1.

Figure 1 The change in the \% of children in the upper secondary non-public sector from 2000 to $2012 .^{2}$

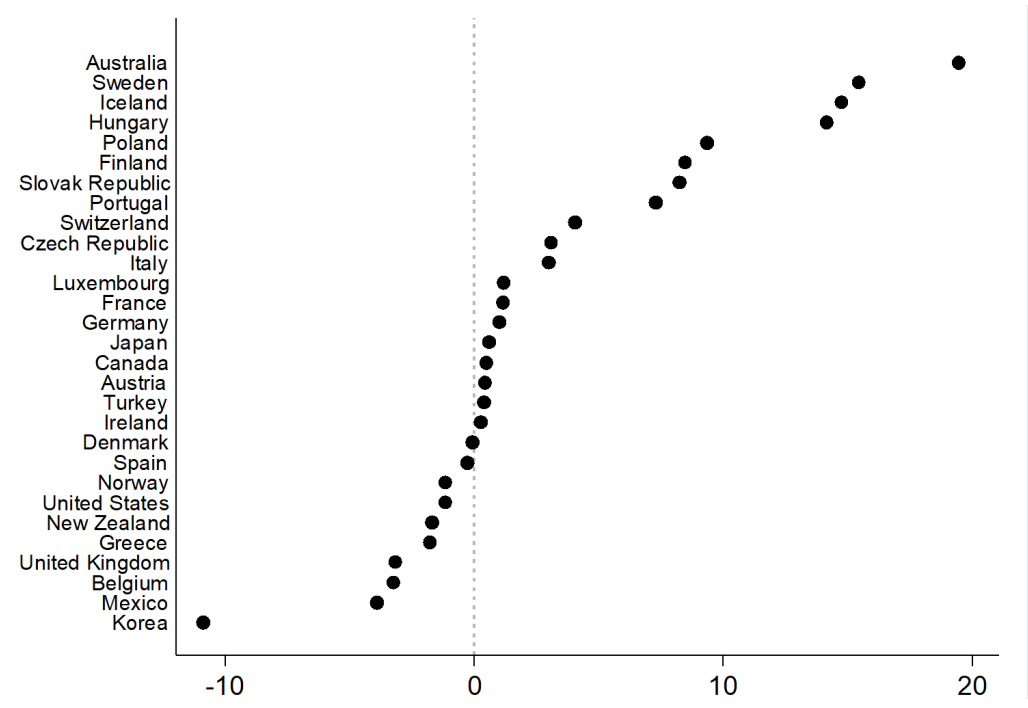

Tuition fees represent one of the most significant expenditure items for parents of children attending these private schools. Currently in Australia, the median annual tuition fee for a child in a private secondary school is approximately $15 \%$ of median equivalised disposable income for couples with dependent children. ${ }^{3}$ Parents who want an accurate source for information on tuition fees changes have only media reports and the education

\footnotetext{
2 Calculated by comparing the number of upper secondary school students using OECD (2014) (Table C1.5) and OECD (2003) (Table C2.4). The data for The Netherlands was not consistent for both years.

3 Equivalised disposable income accounts for the variation in actual household sizes to enable cross household comparisons see Appendix 3 of $A B S$ (2007) for details.
} 
subgroup of the consumer price index $(C P I)$ generated by the Australian Bureau of Statistics $(A B S)$. Most local media reports focus only on increases in tuition fees among an "elite" group of private schools with an emphasis on comparisons to the overall rate of inflation (e.g. Marshall et al. 2013). The $A B S$ produces a price index for the education subgroup of the consumer price index however it combines both tuition fees at private schools and additional "voluntary" contributions and costs at government schools (also known as Public or State schools and are free for all Australian citizens and permanent residents). Prior to the analysis conducted here, there has been very little research in the nature of the price changes in tuition fees across the different types of schools and their locations.

The focus of this paper is a detailed examination of the change in the fees charged by private secondary schools in the Australian state of Victoria using an econometric model applied to a unique panel data set of school characteristics and fees for the period from 2001 to 2013. By 2013, Victoria had a population of 5.5 million and over 27\% of all Australian secondary students enrolled in independent schools. Over this period the annual growth rate in the secondary education subgroup of the $C P I$ for metropolitan Victoria was reported as $6.4 \%$ compared to an overall annual inflation rate for the total CPI of approximately $3 \%$. However, observations of fee inflation do not take into account: the diversity of private schools by location, the socioeconomic characteristics of the student's backgrounds, or any adjustments made for changes in the quality and characteristics of the services provided. Our panel data set allows us to estimate hedonic models of secondary education for both baseline and quality-adjusted price indices for tuition fees. As well as define these indices for different subgroups of the private schools.

The private school sector is comprised of Catholic and independent schools. The majority of the Catholic schools are referred to as "Systemic Schools" and they are controlled centrally by the Catholic Education Office. Schools in the independent sector have varying 
degrees of religious affiliation and are administered by separate boards. Tuition fees charged by Australian private schools vary considerably. Tuition fees charged by Catholic systemic schools tend to be modest compared to those in the independent sector. Private schools are also differentiated by location. Approximately $30 \%$ of students attend private schools outside of the metropolitan Melbourne area. ${ }^{4}$ The majority of recent growth in the independent sector has been in schools that charge the lowest fees and those that are outside the metropolitan area.

Another feature of Australian private schools is the degree to which they rely on government funding (from both the Australian Commonwealth and the State and Territorial governments). In 2013, private schools in Victoria received amounts that ranged from 11\% to $87 \%$ of their total annual recurrent funding from both government sources. Thus to varying degrees these schools resemble Charter schools in that they are governed by independent boards but receive significant funding from government sources. Details of the history and structure of Australian private schools can be found in Caldwell (2010).

The rest of the paper proceeds as follows. Section 2 describes the unique panel data assembled to describe the private school sector in Victoria. In Section 3 we define the hedonic price model to be estimated. Secondary education baseline and quality-adjusted price indices for tuition fees for a number of school types are constructed in Section 4 along with an interpretation of the implications of the indices that we have constructed.

Specifically, we employ these constructed indices to examine over the sample period: differences in tuition increases for school types; affordability of tuition for families; how tuition changes are affected by the business cycle and what has happened to the quality of the school services provided. Our conclusions and recommendations are given in Section 5.

\footnotetext{
4 The education subgroup of the CPI is only based on prices for households in the eight State and Territory capital cities and does not cover the regional areas in any state or Territory.
} 


\section{Description of the Data}

Although the data we have assembled come from a range of sources, the schools we examine are private Victorian schools that offer the senior school secondary qualification referred to as the Victorian Certificate of Education $(V C E) .{ }^{5}$ The year 12 tuition (year 12 is the last year of secondary school), enrolment, curriculum options, extra curricula activities and exam performance from 2001-2013 are from the Victorian version of the Good Schools Guide (2001-2013). The level of funding from the Federal Australian government is obtained for individual schools from the Victorian Department of Education and from submissions made to the Australian Senate Education, Employment and the Federal Workplace Relations Committee in Estimates hearings. Victorian State funding data is obtained from the national My School website for 2009-2013. ${ }^{6}$ For years 2001-2008 we use the total amount of State funding published in the National Report on Schooling. We observe up to 171 schools although the data set has is an unbalanced panel due to the appearance of new schools and the amalgamation of others over this period. Where possible, we interpolate missing values for inter-year gaps due to inconsistency in reporting in some of the school characteristics.

\subsection{A Classification of schools by Region, Administration and Parent's Socioeconomic Status}

Due to the wide variation in their characteristics we perform our analysis using two different methods for the categorisation of these schools. In the first, we divide the schools into two groups by location: either they are located in the Melbourne metropolitan area or in regional Victoria. In the second, we sub-divide all non-government schools into four groups: schools in the Catholic School System (referred to as Systemic) and all others (often referred

\footnotetext{
5 Most all private schools in Victoria offer the VCE although there are some that also offer the International Baccalaureate as well.

6 The Department of Education website is https://education.gov.au/; the website for the Senate Education, Employment and Workplace Relations Committee in Estimates hearings is www.aph.gov.au and the My School website is www.myschool.edu.au
} 


$$
(100 \leq S E S<115)) \text { and high }
$$

$(S E S \geq 115) .{ }^{7}$ In Victoria SES values range from 80-130 with an average value of 107.

The use of the $S E S$ to distinguish different schools is based on the observation that socio-economic segregation in schools has become increasingly pronounced in Australia (see Perry 2012). Table 1 compares the SES for groups of schools defined by location and administration. This table illustrates that high SES schools tend to be located in the metropolitan region and a large percentage of low SES schools are located in regional Victoria. Additionally, the systemic Catholic schools tend to have low and middle $S E S$ parents and the majority are located outside of metropolitan Melbourne. This table also shows that independent schools cater to families at all levels of SES.

Table 1 Comparison of Schools by SES and other characteristics

\begin{tabular}{|l|r|r|r|r|}
\hline Categories & Low (\%) & Middle (\%) & High (\%) & \# of Schools \\
\hline All Schools & 35.1 & 42.7 & 22.2 & 171 \\
\hline Independent & 23.8 & 40.6 & 35.6 & 101 \\
\hline Systemic & 51.4 & 40.0 & 8.6 & 70 \\
\hline Metro & 24.6 & 45.2 & 30.2 & 126 \\
\hline Regional & 64.4 & 35.6 & 0.0 & 45 \\
\hline
\end{tabular}

\subsection{Measures of Government support for Private Schools}

All the private schools examined here receive some support directly from both the State and the Australian Commonwealth governments. The Australian Commonwealth is the main public funding source for private schools providing more than $70 \%$ of the total government funding. Since 2000 this level of funding per student has been determined by a number of $S E S$ based funding formulae. Private schools are allocated a proportion of the cost

\footnotetext{
7 The SES measure used is based on scores used to distribute Australian Government recurrent grants to private schools. Student residential addresses are linked to Australian Bureau of Statistics national census data to obtain a socioeconomic profile of the school community.
} 
of educating a student in a government school referred to as the Average Government School Recurrent Costs (AGSRC). In the 2012/13 financial year Commonwealth total funding to private schools was $\$ 8.1$ billion. While the States and Territories contributed approximately an additional $\$ 3$ billion. Figures $2 \mathrm{a}$ and $2 \mathrm{~b}$ plot the average recurrent per student Commonwealth and State grants respectively. These figures illustrate that the average per student grants have been increasing with the Commonwealth grants being higher than the State grants. Furthermore, they also show the extent to which the funding for low $S E S$, regional and systemic schools has been greater than for metropolitan, middle and high SES schools.

Figure 2 Recurrent per student government funding by types of private secondary schools (in current $\$ \mathrm{Au}$ )

Figure 2a: Commonwealth Funding (\$)

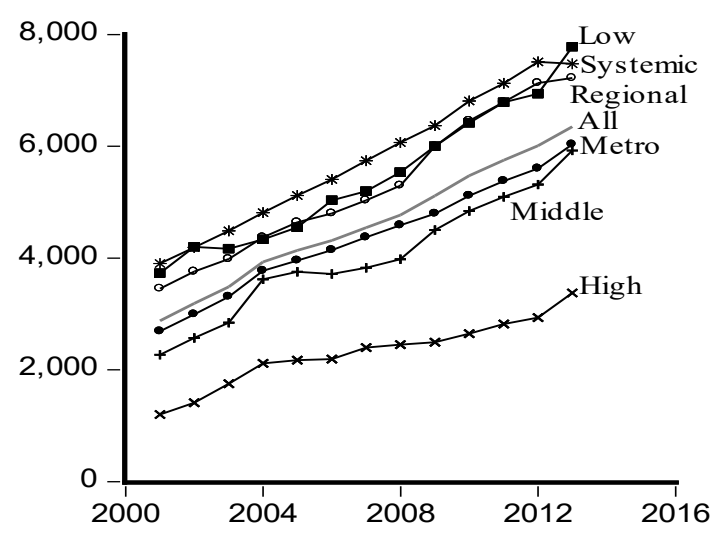

Figure 2b: State Funding (\$)

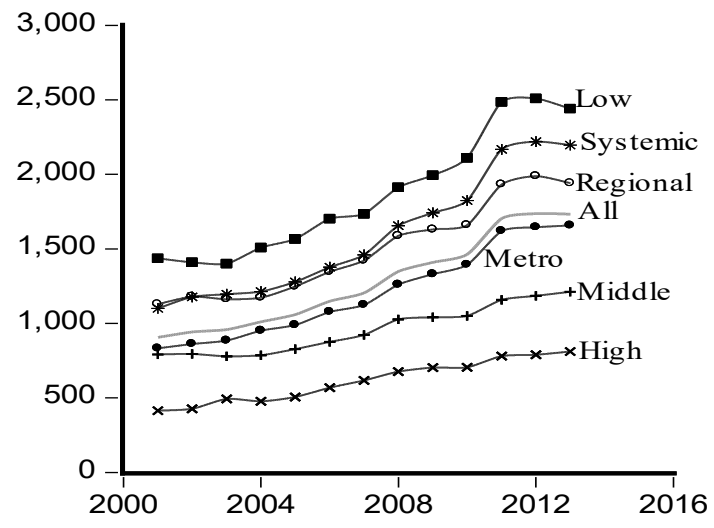

\subsection{Private School Tuition Fees}

Figure 3a plots the time series of the average for year 12 fees by type of school. This figure shows the considerable variation in tuition fees and their rate of change for the different school types. Some of the greatest increases have been in the high SES schools. Figure $3 b$ provides a scatter plot of the 2013 fees versus the school's SES. Each point is identified as either a systemic Catholic or an independent school. Thus, although there is an increase in fees with the level of $S E S$, it can be noted that systemic Catholic schools charge lower fees than independent schools. 
Figure 3 Private School Year 12 Tuition fees in current \$AU by year and type and SES in 2013
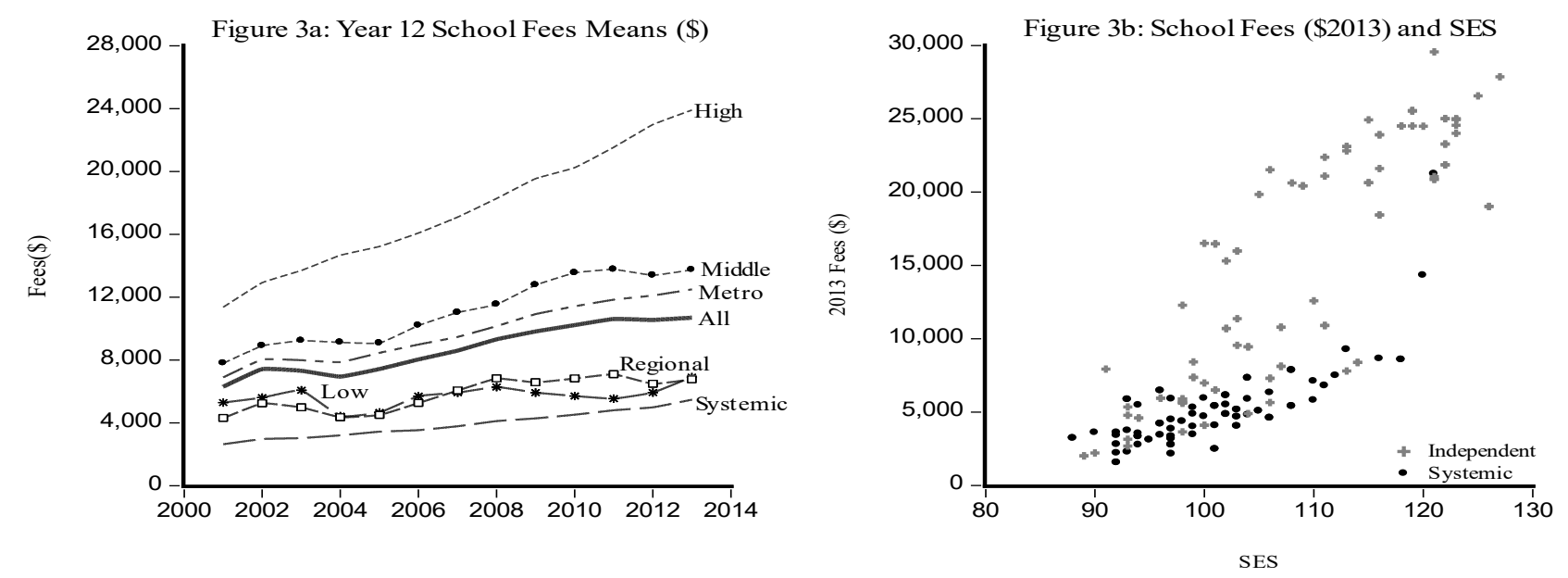

To put these fees in perspective, Table 2 provides the average fees charged in other countries for similar education services. From this table we see that the mean tuition for the high SES type school could be considered at the higher end of US undergraduate tuition.

Table 2 Tuition fees in other countries by comparison $(\$ A U)^{8}$

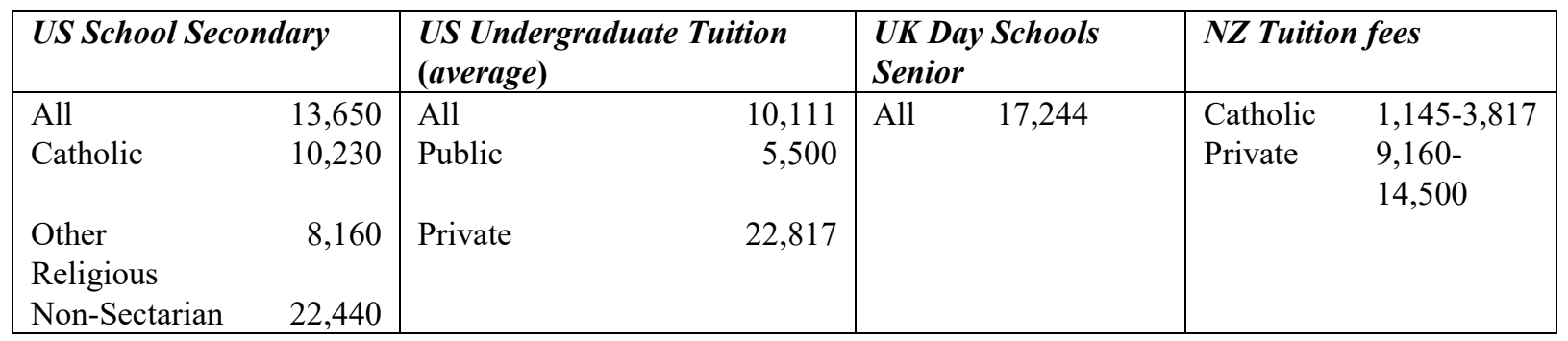

Figure 4 compares the sum of the fees and government recurrent funding for private schools by category with the total per capita expenditure on equivalent Government schools in Victoria as reported for Victoria by the Australian Curriculum, Assessment and Reporting Authority (2013). From this figure it can be noted that for low SES, regional and systemic Catholic schools tuition fees and Government recurrent funding combined is similar to the per capita expenditure for Government secondary schools. However, for middle and high

\footnotetext{
8 Exchange Rate used: 1AU=\$1US; $1 \mathrm{AU}=.67 \mathrm{GBP}$ Sources; $1 \mathrm{AU}=\$ 1.31 \mathrm{NZ}$ : Digest of Education Statistics 2013 Table 205.50; 2012 Table 381; Independent Schools Council Annual Census. Catholic Schools in UK are state funded. Catholic schools in New Zealand are state-integrated although parent must pay compulsory attendance dues. Data for US and UK are based on 2012 and for NZ the data are from 2011.
} 
$S E S$, and metropolitan schools, fees and Government recurrent funding combined is much higher than the per capita expenditure for Government secondary schools.

Figure 4 Comparison of total funding per student for Victorian Secondary Schools. (Tuition plus total Government Recurrent Funding with Per capita expenditure for Government schools (in current \$AU))

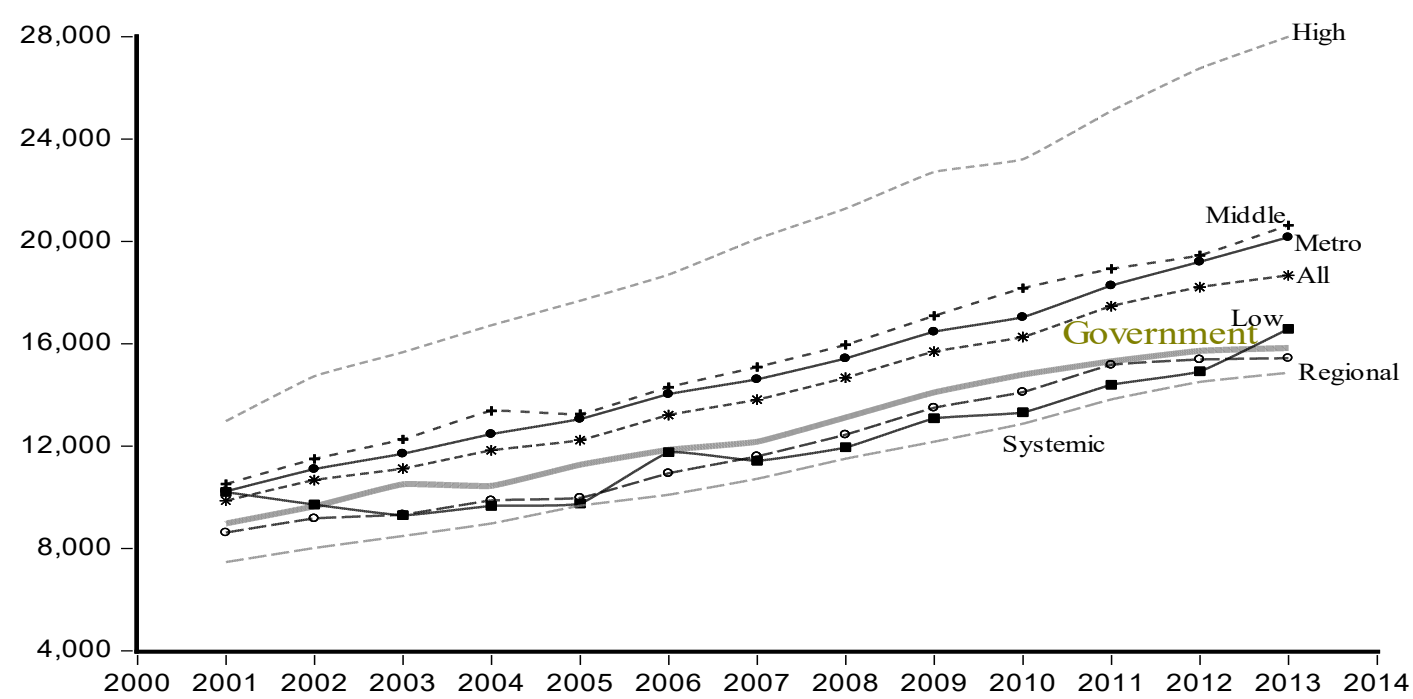

\subsection{Time Varying Measures of School Performance and Offerings}

The majority of secondary students in Victoria complete a VCE (Victorian Certificate of Education) program which allows the examination in a number of different subjects. Most of these subjects consist of four semester length units usually taken over a two year period in the last years of high school. The marks are scaled from 0 to 50 and scores above 40 are considered as high achievement in specific subjects. Table A.1 in Appendix A reports the mean number of scores in all $V C E$ subjects where scores of 40 or more have been earned by school type for 2001, 2005, 2009 and 2013. The mean number of these results for all private schools has fallen from 13 in 2001 to 11 in 2013. However, for the high and middle $S E S$ schools the means have remained fairly steady around 22 and 12 respectively, while the mean number of $40+$ scores has fallen from 12 to 8 for the low SES schools. Over this period the Systemic schools have maintained a mean of 8 while the non-systemic schools mean has fallen from 17 to 14 . 
Another performance characteristic collected for each school was the percentage of leaving students who attended a university in the following year. This median percentage has fallen over this period for all types of SES level categories except the lowest group which initially dropped but has returned to the original level. Over all schools the median percentage has fallen by $4 \%$ from $84 \%$ to $80 \%$, this has occurred for systemic, non-systemic, and metropolitan schools, with regional schools maintaining a median of $74 \%$.

We have also compiled the number of: $V C E$ subjects, languages, sports options and other cocurricular options. Table A.1 in Appendix A also reports the means for these variables. All show monotonic increases over time for all types of schools. Over this period there has been an average increase from 28 to 39 in the number of $V C E$ subjects offered. However, the mean for the lowest SES category schools only increased from 20 to 24.

Table A.1 also records the enrolment changes. Low SES schools had the biggest percentage increase over the sample period. The percentage increase in regional Victoria was more than double than in the metropolitan area. Only for high SES schools was the percentage increase minimal.

\section{Hedonic Price Model of Tuition Fees}

For this analysis we assume the market for private schools is composed of numerous schools that offer differentiated services consisting of a bundle of characteristics. Court (1939) first proposed using a hedonic model to construct a price index. This approach has been applied to generate price indices for such diverse goods and services as: automobiles Griliches (1961); pesticides (Fernandex-Cornejo and Jans 1995); laptop computers (Chwelos 2003); new passenger cars (van Dalen and Bode 2004) and US Colleges (Schwartz and Scafidi 2004). In a hedonic model a service such as education can be viewed as comprising a bundle of characteristics. These characteristics contribute to the utility derived from its use (Rosen 1974). The price of this bundle is assumed to equal the sum of the "implicit" prices 
of the characteristics that constitute the service. Consumers can only buy characteristics in bundles and the price of the bundle, in this case the tuition fee, is observed. Thus we assume that the tuition fees paid for year 12 private high school are indicative of the value placed on the education and other added services provided by the school. A hedonic model of tuition fees allows a decomposition of the tuition fees into fees paid for the constituent elements of the entire educational service.

We adopt a log-linear specification in which the logarithm of fees at the $j^{\text {th }}$ school at year $t\left(P_{j t}\right)$. In the first specification we model fees as a function of fixed effects for years, schools and the time varying characteristics:

$$
\underbrace{P_{j t}}_{\substack{\text { Log of yr } \\
12 \text { fees }}}=\alpha+\underbrace{\sum_{t=1}^{T} \rho_{t} D_{t}}_{\begin{array}{c}
\text { Time Fixed } \\
\text { Effects }
\end{array}}+\underbrace{\sum_{\substack{\text { Schoo Time } \\
\text { School Fixed } \\
\text { Effects }}}^{J} \beta_{j} S_{j}}_{\begin{array}{c}
\text { Sarying Characteristics } \\
\sum_{k=1}^{K} \gamma_{k} X_{k j t}
\end{array}}+\varepsilon_{j t}
$$

where $j=1 \ldots J, t=0 \ldots T, S_{j}$ is an indicator variable that takes the value 1 for School $j$ and $D_{t}$ indicates the year equal to 1 for year $t, k=1 \ldots K$ and $X_{k j t}$ is the $k$ th year varying school characteristic of school $j$ at year $t$. The coefficients $\alpha, \beta_{2} \ldots \beta_{J}, \gamma_{1} \ldots \gamma_{K}, \rho_{1} \ldots \rho_{T}$ are coefficients to be estimated and the error term $\varepsilon_{j t}$ is assumed to be identically and independently distributed, however we will account for possible violations of this assumption in our estimation.

The estimates of $\rho_{t}$

$\rho^{\prime} s$. Employing the procedure used in Fernandex-Cornejo and Jans (1995), Chwelos (2003), van Dalen and Bode (2004) and Schwartz and Scafidi (2004), the estimated price index at time $t+1$ is defined as 
$100 \exp \left(\hat{\rho}_{t+1}\right)$, at time $t+2$ is $100 \exp \left(\hat{\rho}_{t+2}\right)$ up to $t=12$ for 2013 thus the estimated Average Annual Growth Rate $\widehat{A A G R}=100\left(\exp \left(\hat{\rho}_{13} / 12\right)-1\right)$.

In the second regression (2) schools are classified by location. Thus an indicator variable $M$ is defined as equal to 1 for schools in the Melbourne metropolitan area and 0 for all others. This indicator is interacted with the: year fixed effects and with the time-varying characteristics for each school. This model also includes the school fixed effects.

$$
\underbrace{P_{j t}}_{\substack{\text { Log of yr } \\
\text { 12 fees }}}=\alpha+\underbrace{\sum_{t=1}^{T}(\underbrace{\rho_{t} D_{t}}_{\text {All }}+\underbrace{\delta_{t}\left(M_{j} * D_{t}\right)}_{\text {Metro }})}_{\text {Time Fixed Effects }}+\underbrace{\sum_{k=1}^{K}(\underbrace{\gamma_{k} X_{k j t}}_{\text {All }}+\underbrace{\tau_{k}\left(M_{j} * X_{k j t}\right)}_{\text {Metro }})}_{\text {School Time Varying Characteristics }}+\underbrace{\sum_{j=2}^{J} \beta_{j} S_{j}}_{\begin{array}{c}
\text { School Fixed } \\
\text { Effects }
\end{array}}+\varepsilon_{j t}
$$

where $\alpha, \beta_{1} \ldots \beta_{J}, \gamma_{1} \ldots \gamma_{K}, \tau_{1} \ldots \tau_{K}, \rho_{1} \ldots \rho_{T}, \delta_{1} \ldots \delta_{T}$ are coefficients to be estimated and the two price indices from this model would involve either just the estimates of $\rho_{t}$ for the regional schools or the sum $\left(\rho_{t}+\delta_{t}\right)$ for the metropolitan schools.

In the third regression specification (3) we classify schools into four groups: systemic Catholic and three types of other independent schools defined by the level of the SES of the parents from Section 2.1 as: high, middle or low. Each of these categories is interacted with the year fixed effects along with the time varying school characteristics. As with the other models the school specific fixed effects are also included.

$$
\begin{aligned}
\underbrace{P_{j t}}_{\substack{\text { Log of yr } \\
\text { 12 fees }}}= & \alpha+\underbrace{\sum_{t=1}^{T}(\underbrace{\rho_{t} D_{t}}_{\text {All }}+\underbrace{\lambda_{t}\left(S C_{j} * D_{t}\right)}_{\text {Catholic }}+\underbrace{\pi_{t}\left(H_{j} * D_{t}\right)}_{\text {High SES }}+\underbrace{\theta_{t}\left(L_{j} * D_{t}\right)}_{\text {Low SES }})}_{\text {Time Fixed Effects }} \\
& +\underbrace{\sum_{k=1}^{K}(\underbrace{\gamma_{k} X_{k j t}}_{\text {All }}+\underbrace{v_{k}\left(S C_{j} * X_{k j t}\right)}_{\text {Catholic }}+\underbrace{\psi_{k}\left(H_{j} * X_{k j t}\right)}_{\text {High SES }}+\underbrace{\xi_{k}\left(L_{j} * X_{k j t}\right)}_{\text {Low SES }})}_{\text {School Time Varying Characteristics }}+\underbrace{\sum_{\text {Effects }}^{j} \beta_{j} S_{j}}_{\text {School Fixed }}+\varepsilon_{j t}
\end{aligned}
$$

where $\alpha, \beta_{1} \ldots \beta_{J}, \rho_{1} \ldots \rho_{T}, \gamma_{1} \ldots \gamma_{K}, v_{1} \ldots v_{K}, \psi_{1} \ldots \psi_{K}, \xi_{1} \ldots \xi_{K}, \lambda_{1} \ldots \lambda_{T}, \pi_{1} \ldots \pi_{T}, \theta_{1} \ldots \theta_{T}$ 
$\left(\rho_{t}+\lambda_{t}\right),\left(\rho_{t}+\pi_{t}\right)$, and $\left(\rho_{t}+\theta_{t}\right)$ to construct a price index for systemic Catholic, high and low SES schools respectively.

\section{Results}

In this section we describe the results of the estimated hedonic price models defined to construct the baseline and quality-adjusted price indices for different subgroups of private schools. We make comparisons between the constructed price indices with the official CPI and its education subgroup as well as a number of other series. We also examine what has happened to the affordability of tuition fees for different subgroups of private schools, as well as the impacts of macroeconomic fluctuations on fee changes.

\subsection{Baseline Price Indices}

Baseline price indices are estimated by assuming the school time varying parameters are equal to 0 in equations (1), (2), or (3). Thus only school and year fixed effects are included in each equation. The final specification of each equation was determined by jointly testing the coefficients for school and year fixed effects. The results of these tests are reported in Table A.2. The $F$-statistic for the joint test of the coefficients in equation (3) on the interactions between year fixed effects and the indicator variables for systemic Catholic and high SES schools was consistent with the hypothesis that the coefficients for these interactions are equal to zero. Thus they have been removed from the specification and the baseline price index presented for systemic Catholic and high SES schools will be the same as the baseline price index constructed for middle SES schools.

The price indices and the corresponding $\widehat{A A G R}$ 
the $A B S$ price index for secondary education in Melbourne. ${ }^{9}$ The $\widehat{A A G R}$ for all private schools was around $6.6 \%$ per year which implies that the price index increased approximately $6.6 \%$ per year over the $2001-2013$ time period compared to a $6.4 \%$ per increase associated with the secondary education category of the CPI. Across the subgroups though there were significant differences. It was marginally higher at $6.8 \%$ per year for metropolitan schools whereas for regional schools the estimated increase was only about $6.0 \%$ per year. For middle $S E S$, high $S E S$ and Systemic schools the increase in the price index was similar to that obtained for all private schools at $6.7 \%$ per year over this time period whereas the increase for low SES schools was estimated at the much lower rate of $5.8 \%$ per year.

Table 3 Baseline Price Indices (model specification)

\begin{tabular}{|c|c|c|c|c|c|c|}
\hline Year & $\begin{array}{l}A B S \\
C P I \\
\end{array}$ & All (1) & Metro (2) & Regional (2) & $S+M+H(3)^{\dagger}$ & $\operatorname{Low}(3)^{\dagger}$ \\
\hline Formula & & $100 \exp \left(\hat{\rho}_{t}\right)$ & $100 \exp \left(\hat{\rho}_{t}+\hat{\delta}_{t}\right)$ & $100 \exp \left(\hat{\rho}_{t}\right)$ & $100 \exp \left(\hat{\rho}_{t}\right)$ & $100 \exp \left(\hat{\rho}_{t}+\hat{\theta}_{t}\right)$ \\
\hline 2001 & 100.0 & 100.0 & 100.0 & 100.0 & 100.0 & $\overline{100.0}$ \\
\hline 2002 & 106.6 & 111.0 & 112.1 & 107.2 & 111.1 & 107.9 \\
\hline 2003 & 113.0 & 119.3 & 120.2 & 116.0 & 119.4 & 115.6 \\
\hline 2004 & 119.9 & 126.5 & 127.7 & 121.8 & 126.5 & 120.2 \\
\hline 2005 & 127.7 & 135.1 & 137.3 & 127.2 & 135.4 & 126.7 \\
\hline 2006 & 135.4 & 140.0 & 142.1 & 132.6 & 140.6 & 125.7 \\
\hline 2007 & 143.7 & 148.5 & 150.3 & 141.6 & 149.0 & 136.2 \\
\hline 2008 & 152.0 & 158.4 & 160.9 & 149.0 & 158.7 & 149.1 \\
\hline 2009 & 165.2 & 172.4 & 175.0 & 162.6 & 172.4 & 165.7 \\
\hline 2010 & 173.5 & 183.4 & 185.9 & 173.8 & 183.5 & 173.4 \\
\hline 2011 & 186.8 & 190.2 & 194.1 & 176.3 & 190.9 & 173.9 \\
\hline 2012 & 200.0 & 202.2 & 206.1 & 188.5 & 203.0 & 185.3 \\
\hline 2013 & 209.7 & 216.0 & 220.8 & 200.6 & 217.5 & 195.5 \\
\hline $2013-2001$ & 109.7 & 116.0 & 120.8 & 100.6 & 117.5 & 95.5 \\
\hline$\widehat{A A G R}$ & 6.4 & 6.6 & 6.8 & 6.0 & 6.7 & 5.8 \\
\hline
\end{tabular}

${ }^{\dagger}$ This is a modified version of specification (3) under the assumption that $\lambda_{t}=\pi_{t}=0$ which is equivalent to assuming that the $A A G R$ for Systemic Catholic, middle SES, and high SES schools are the same.

\footnotetext{
9 This series is entitled Index Numbers; Secondary education; Melbourne, (id A2331481L), from TABLE 11. CPI: Group, Sub-group and Expenditure Class, Index Numbers by Capital City, from $A B S 2014$.
} 


\subsubsection{Comparison of Baseline Indices with other Series}

Figure 5 provides a comparison between the $\widehat{A A G R}$ calculated from the baseline price indices with the $A A G R$ calculated from a range of other series over 2001-2013. The $\widehat{A A G R}$ s calculated from the baseline price indices are shaded in black. The other $A A G R$ was lowest for the consumer price index $(C P I)$ and the services only subgroup of the $C P I$ for Victoria. These price indices increased between only 2.6 and $3.4 \%$ per year. One justification for the increases in tuition fees each year is the rising cost of teacher salaries (Fraser and Nadin 2014). The average annual growth rate was also calculated for a number of wage price series that were related to teacher salaries. These indicated increases in salaries between $3.5-4.5 \%$ per year.

Figure 5 Average Annual Growth Rate for Base Price Indices and other series

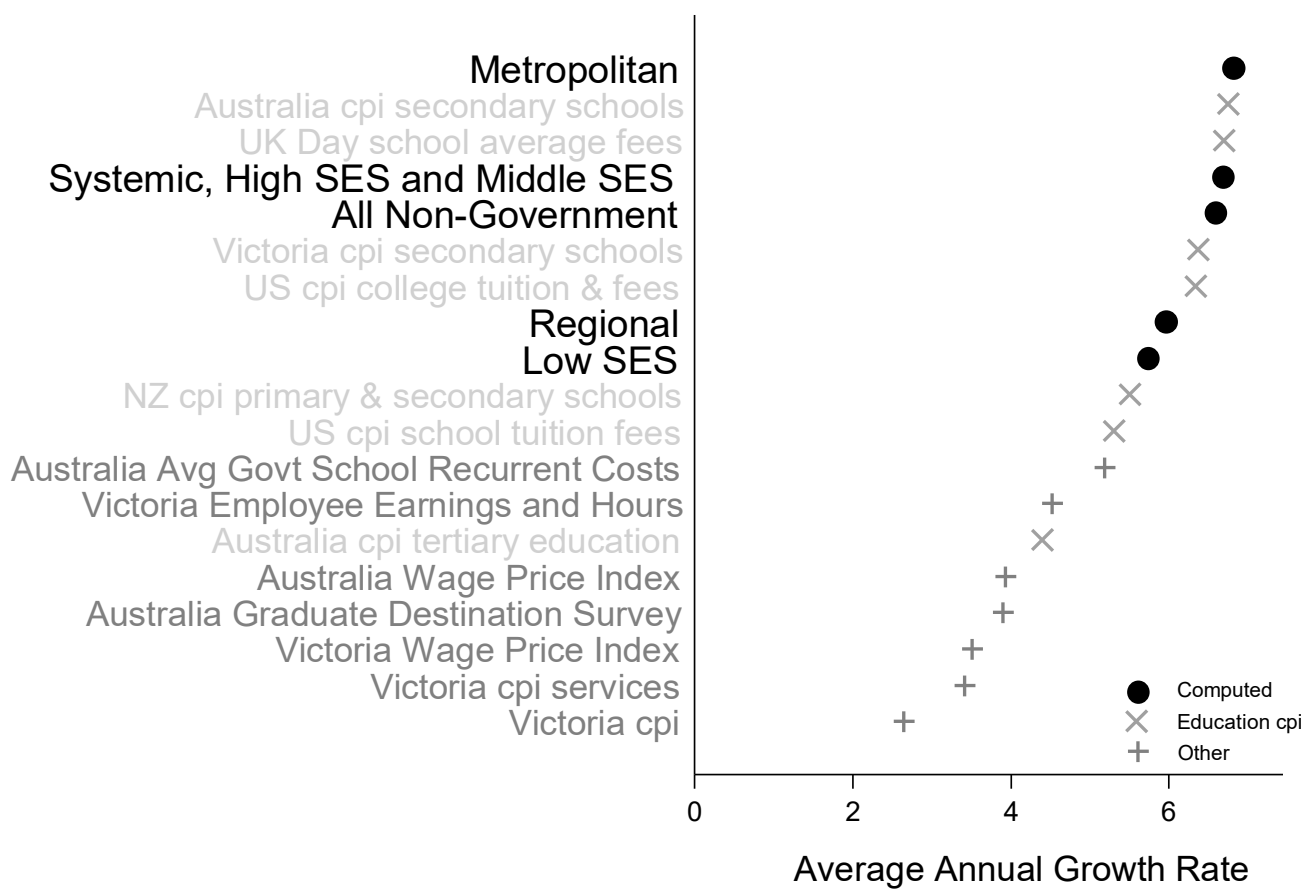

The Average Government School Recurrent Costs (AGSRC) measures the annualized cost of educating a student at a government school. Gonski (Gonski et al. 2011) proposes that the growth in $A G S R C$ for government educational services is mainly driven by teacherrelated expenses due to wages growth and reductions in student-staff ratios. Private schools 
are allocated government funds as a proportion of $A G S R C$ to each student they enrol according to a sliding scale based on the SES of the parents of the children that attend the school where the highest $S E S$ schools receive the least and the lowest receive the most. The $A A G R$ for the $A G R S C$ was slightly higher at $5.1 \%$ per year which was similar to the $A A G R$ for the school tuition subgroup of the US CPI.

The baseline price indices as reported in Table 4 have similar $A A G R$ 's to those calculated for other series based on education fees as can be seen in Figure 5. The baseline price indices $A A G R$ for all private schools and the metropolitan, systemic, high $S E S$ and middle SES subgroups was not significantly different at the $5 \%$ level of significance to the $A A G R$ calculated for the Australian secondary school $C P I$ subgroup as well as for independent day tuition fees in the UK. Regional schools had an $A A G R$ that was not significantly different at the $5 \%$ level of significance to the $A A G R$ calculated for the college tuition subgroup of the US CPI. The low SES schools had an $A A G R$ that was not significantly different at the $5 \%$ level of significance from the $A A G R$ for the school tuition subgroup of the US and New Zealand CPI .

\subsubsection{Tuition Fees and Family Affordability from the Baseline indices}

Table 4 reports percentages of students in private schools in Victoria for 422 census statistical areas (SA2) in Victoria categorised by quintiles of the area average incomes of families with children for 2001 and 2011 the Australian census data $(A B S, 2012) .{ }^{10}$ From this table it can be seen that the total percentage of Victorian secondary students enrolled in a private school increased from $39 \%$ to $44 \%$. It can also be noted that over this period, the percent of privately educated secondary students from families living in areas with the

\footnotetext{
10 This table is based on 422 SA2 statistical areas as defined in the 2011 Census located in Victoria with 100 or more persons in both the 2001 and 2011 Censuses. The median population of the SA2s in Victoria is approximately 10,000. The income quantiles are based on the average reported family incomes with at least one child under the assumption of a lognormal distribution of income.
} 
highest income stayed constant. Thus the increase in private secondary school attendance was mainly from areas where families have lower income levels.

Table 4 Percentage of secondary school students in private schools (Independent or Catholic) in Victoria and \% growth in the number of secondary school students from 2001 to 2011 in $A B S$ Statistical Areas (SA2) categorised by quintile of average family income.

\begin{tabular}{|c|rrr|cc|}
\hline Income & \multicolumn{3}{|c|}{ \% change in number - 2001 to 2011 } & \multicolumn{2}{c|}{ \% in Private Schools } \\
Quintile & Independent & Catholic & All Schools & 2001 & $\mathbf{2 0 1 1}$ \\
\hline$<\mathbf{2 0 \%}$ & 57 & 11 & 1 & 26 & 32 \\
$\mathbf{2 0 - 4 0 \%}$ & 34 & 11 & 0 & 32 & 37 \\
$\mathbf{4 0 - 6 0 \%}$ & 46 & 18 & 13 & 36 & 41 \\
$\mathbf{6 0 - 8 0 \%}$ & 26 & 18 & 7 & 41 & 46 \\
$>\mathbf{8 0 \%}$ & 3 & 2 & 2 & 60 & 60 \\
\hline All Victoria & 21 & 12 & 4 & 39 & 44 \\
\hline
\end{tabular}

Number in $\mathbf{2 0 1 1} \quad 69,522 \quad 82,229 \quad 345,734$

Table 4 also provides a breakdown of the growth in student numbers from 2001 to 2011 by quintile of average family income in the census area and by type of school. Note that the greatest percentage increase occurred for students from the lowest quintile areas that enrol in an independent school. The proportion of secondary students in private schools was most stable in the highest income quintile areas. If we account for the increase in all secondary students in these statistical areas we find that the number of students in the $20 \%$ to $60 \%$ income quintiles areas that attend independent schools has grown by approximately $33 \%$. Thus from Table 4 we can see that the majority of the growth in private secondary enrolment has been from lower family income areas, while demand for private school places has remained constant in the highest quintile family income areas. 
Table 5 Affordability as defined by the \% of Mean Equivalised Disposable Household Income to pay for one year of Secondary Tuition Fees by quintile and secondary school type.

\begin{tabular}{|c|c|c|c|c|c|c|c|c|}
\hline \multirow{2}{*}{$\begin{array}{l}\text { Income } \\
\text { Quintile }\end{array}$} & \multicolumn{2}{|c|}{ High SES } & \multicolumn{2}{|c|}{ Middle SES } & \multicolumn{2}{|c|}{ Low SES } & \multicolumn{2}{|c|}{ Systemic Catholic } \\
\hline & 2001 & 2012 & 2001 & 2012 & 2001 & 2012 & 2001 & 2012 \\
\hline$<20 \%$ & 86.7 & 128.4 & 56.9 & 72.2 & 32.5 & 30.5 & 18.8 & 26.7 \\
\hline $20-40 \%$ & 52.7 & 77.5 & 34.5 & 43.6 & 19.7 & 18.4 & 11.4 & 16.1 \\
\hline $40-60 \%$ & 37.4 & 57.2 & 24.5 & 32.2 & 14.0 & 13.6 & 8.1 & 11.9 \\
\hline $60-80 \%$ & 27.9 & 43.1 & 18.3 & 24.2 & 10.5 & 10.2 & 6.0 & 8.9 \\
\hline$>80 \%$ & 17.5 & 26.1 & 11.5 & 14.7 & 6.6 & 6.2 & 3.8 & 5.4 \\
\hline
\end{tabular}

The change in percentages of students from the lower income families attending private schools may be due to the affordability of these schools. We follow Karikari and Dezhbakhsh (2013) who define affordability for colleges in the US as the ratio of fees to family income. ${ }^{11}$ Table 5 reports the percent of equivalised disposable annual income needed for tuition fees for one year 12 secondary student for one year by family income quintile. In this analysis we distinguish the private school tuition by the type of school as classified above. In Table 3 the distribution of the equivalised disposable income is divided into five quintiles. From this table we find that the only group of schools which have become more affordable over this period are the low SES schools. High and middle $S E S$ schools are only affordable to the highest income quintile families while Systemic Catholic schools still remain the most affordable in 2012.

\subsubsection{Macroeconomic Influences on Private School Tuition Fee}

\section{Growth}

The influence of the macroeconomic climate on the decisions to start and finish university studies has been previously examined by Dellas and Skellaris (2003) and Messer

\footnotetext{
11 Unlike the US colleges that provide financial aid on an inverse scale to family income, the majority of the private schools in this study do not publically acknowledge the degree to which they may offer discounts.
} 
and Wolter (2010). In this section we examine how the macroeconomic climate may influence the fee setting behaviour of private secondary schools. From 2001 to 2013 the Australian Economy generated periods of both rapid and slow economic growth. In order to measure the changes in the growth of the Australian Economy we employ the Hodrick and Prescott (1997) technique to estimate the business-cycle component of the natural log of the Australian real gross domestic product (GDP). We also have computed the growth rate of the school fees by type of school from the base-line indices in Table 3.

Figure 6 provides a comparison of the percent deviation for the Australian GDP and $\%$ change for the fees for two groups of schools. Those located in the metropolitan Melbourne that were found to have largest annual growth and those schools classed as drawing students from low SES families. The changes in the fees are computed as percent changes in the annual baseline indices on the left axis and displayed by a solid line. Over this period we note that the variation in the growth rate for the low SES school fees appear to be much greater than fee changes that occurred in the metropolitan schools.

The GDP growth rates, as measured by percent deviations, are indicated on the right axis in Figure 6. Three periods of economic slowdown during this period can be identified as occurring in 2003, 2006 and more recently the period associated with the Global Financial crisis 2008-2011.

Figure 6 indicates a positive relationship between annual percentage fee changes and the business cycle. This can be noted by the similarity in the peaks and troughs of the rate of change in the fees for the metropolitan schools and the low SES schools and those of the GDP growth. This would imply that the schools are sensitive to the macro-economy in their decisions to change their fees and thus we may have evidence that fee changes are demand driven as opposed to cost driven. The differential in this relationship between these two types of schools may imply that the income elasticity of the parents of the low $S E S$ schools is 
greater than the equivalent elasticity for the parents in Metropolitan Melbourne. The variation in the income elasticity for education appears to agree with the findings reported by Hashimoto and Heath (1995) and Dynarski et al (2009) who found that income elasticities for education were greatest for middle to low income households. It is interesting to note that there is no such interrelationship to be found between this indicator and the secondary school price index generated by the $A B S$ for Melbourne as listed in column 1 of Table 4.

Figure 6: Annual Percentage School Fee Changes and the Business Cycle
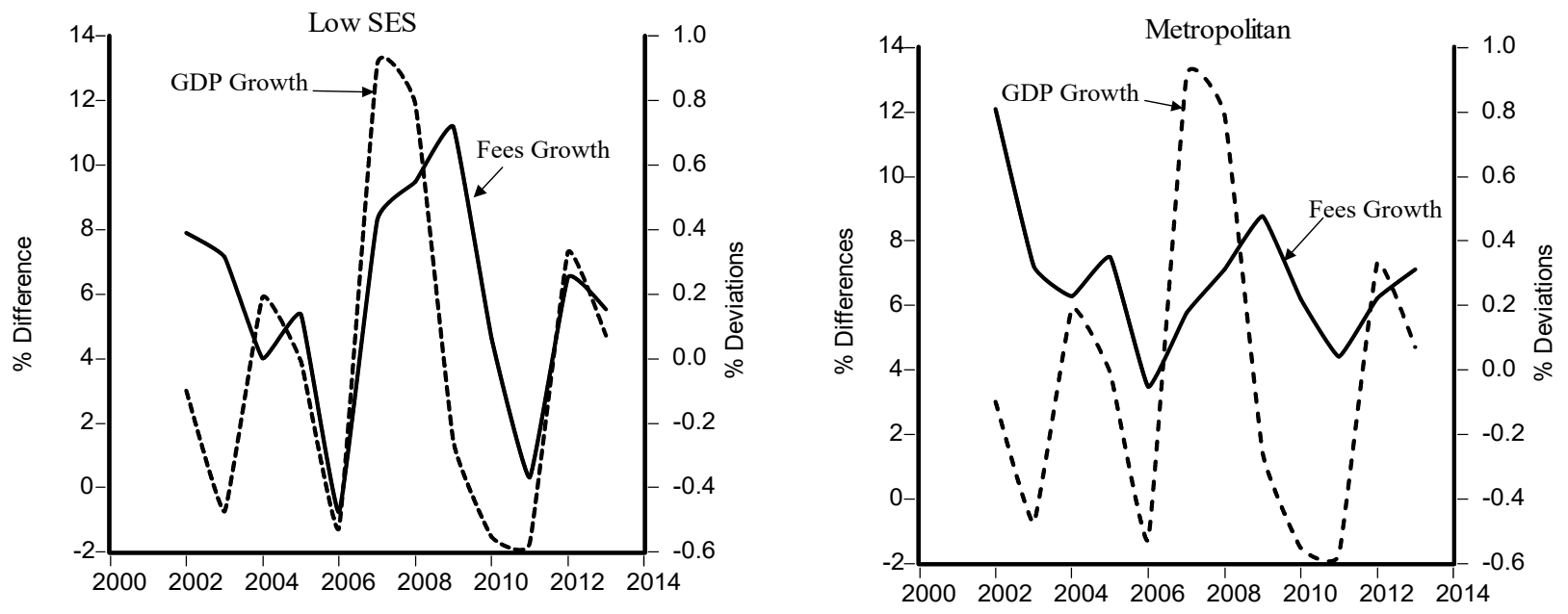

\subsection{Quality-Adjusted Price Indices}

This section presents the results of the quality adjusted price indices as specified in equations (1), (2) and (3) as Section 3, that is in addition to including school and time fixed effects, school time-varying characteristics are also included. The final specification of each equation was based on $F$-tests of the joint significance of coefficients for each group of variables. The results of these $F$-tests are reported in Table A.2. In the final specification no distinctions were made on the coefficients of the time-varying school characteristics between metropolitan and regional schools in (2) and middle and high SES schools in (3). Also, no distinctions were made on the coefficients of the year fixed effects and systemic Catholic, low $S E S$ and middle $S E S$ schools in (1). 
Table 6: Quality Adjusted Hedonic Regression Parameter Estimates ${ }^{12}$

\begin{tabular}{lccccc}
\hline & All & $\begin{array}{c}\text { Metro } \\
\text { \& Regional }\end{array}$ & Systemic & $\begin{array}{c}\text { High } \\
\text { \& Middle }\end{array}$ & Low \\
\hline Log(Number Students) & -0.0078 & 0.0008 & 0.0216 & -0.0157 & -0.0613 \\
VCE units & $0.0024^{* * *}$ & $0.0027^{* * *}$ & $0.0022^{*}$ & 0.0014 & $0.0058^{* * *}$ \\
Language options & 0.0081 & 0.0080 & $0.0255^{* * *}$ & 0.0015 & $-0.0324^{* * *}$ \\
Music options & $2.1 \mathrm{E}-05$ & 0.0001 & -0.0018 & 0.0011 & 0.0135 \\
Sports & -0.0014 & $-0.0017^{* *}$ & $-0.0042^{* *}$ & 0.0008 & -0.0045 \\
Other cocurricular & $0.0007^{* *}$ & $0.0007^{* *}$ & $0.0013^{* * *}$ & 0.0002 & 0.0022 \\
\% study scores 40+ & 0.0001 & $-2.0 \mathrm{E}-05$ & $9.46 \mathrm{E}-05$ & -0.0001 & -0.0036 \\
\% students attend uni & -0.0001 & -0.0002 & -0.0008 & $0.0010^{*}$ & $1.15 \mathrm{E}-05$ \\
Log(Federal Funds) & -0.0194 & $-0.0263^{*}$ & -0.0425 & -0.0131 & $-0.4105^{*}$ \\
Log(State Funds) & -0.0024 & -0.0069 & -0.0190 & 0.0092 & 0.0019 \\
\hline F-statistic & $2.07^{* *}$ & $2.59^{* * *}$ & $1.96^{* *}$ & 1.09 & $4.43^{* *}$ \\
\hline
\end{tabular}

Table 6 lists the estimation results of the coefficients of the time-varying characteristics from specifications based on models (1), (2) and (3). Many of the timevarying characteristics are not individually significant although they are jointly significant except for the high and middle $S E S$ schools. For the full sample as well as metropolitan and regional schools, those that have more $V C E$ units, language and other co-curricular options have higher prices while those with more sports options have lower prices. Those metropolitan and regional schools that receive more federal funds also have lower prices. Systemic Catholic schools offering more co-curricular options have higher prices and those with more sports options have lower prices. Those high and middle SES schools with more sports options have higher prices while for the middle schools with a greater percentage of students going on to tertiary study have higher prices. For the low SES schools those that

\footnotetext{
12 The dependent variable is $\log ($ Fees $)$. Each regression also includes fixed effects for schools and years. The significance levels (* for .1, ** for .05, and *** for .01) are based on standard errors clustered by school. Column 1 is based on the specification defined by equation (1). Column 2 are the parameter estimates of $\gamma_{k}$ from equation (2) when we constrain $\forall \tau_{k}=0$ which implies that location does not matter for the influence of characteristics on fees. Columns 3, 4 and 5 are based on equation (3) when we constrain $\forall \pi_{k}=0$ which implies that characteristics of High SES schools have the same influence as characteristics of Middle SES schools.
} 
have more $V C E$ units and music options have higher prices although those offering more language options and receiving more federal funds have lower prices.

Table 7 presents the quality-adjusted price indices and the corresponding estimated $\widehat{A A G R}$. Introducing quality-adjustments yields a lower $\widehat{A A G R}$ for all, regional and high $S E S$ schools. However, for low $S E S$ schools there is an increase in the resulting $\widehat{A A G R}$.

Thus, the lower $\widehat{A A G R}$ obtained using the baseline price index for low $S E S$ schools is due to the quality of their characteristics in comparison to the other schools. For systemic Catholic and metropolitan schools there was no change in the $\widehat{A A G R}$.

Table 7: Quality Adjusted Price Indices

\begin{tabular}{ccccccccc}
\hline Year & ABS CPI & All & Metro & Regional & Systemic & High & Middle & Low \\
\hline $\mathbf{2 0 0 1}$ & 100.0 & 100.0 & 100.0 & 100.0 & 100.0 & 100.0 & 100.0 & 100.0 \\
$\mathbf{2 0 0 2}$ & 106.6 & 111.3 & 112.6 & 107.1 & 110.8 & 113.7 & 110.8 & 110.8 \\
$\mathbf{2 0 0 3}$ & 113.0 & 118.3 & 119.2 & 114.9 & 118.6 & 119.4 & 118.6 & 118.6 \\
$\mathbf{2 0 0 4}$ & 119.9 & 125.8 & 127.5 & 120.1 & 125.4 & 128.7 & 125.4 & 125.4 \\
$\mathbf{2 0 0 5}$ & 127.7 & 134.5 & 137.5 & 124.9 & 135.3 & 134.4 & 135.3 & 135.3 \\
$\mathbf{2 0 0 6}$ & 135.4 & 138.7 & 141.2 & 129.8 & 139.1 & 141.0 & 139.1 & 139.1 \\
$\mathbf{2 0 0 7}$ & 143.7 & 146.9 & 149.3 & 138.4 & 147.0 & 151.7 & 147.0 & 147.0 \\
$\mathbf{2 0 0 8}$ & 152.0 & 156.7 & 159.9 & 146.1 & 157.3 & 160.0 & 157.3 & 157.3 \\
$\mathbf{2 0 0 9}$ & 165.2 & 170.9 & 174.3 & 159.7 & 172.6 & 171.6 & 172.6 & 172.6 \\
$\mathbf{2 0 1 0}$ & 173.5 & 182.5 & 186.1 & 171.0 & 185.1 & 181.2 & 185.1 & 185.1 \\
$\mathbf{2 0 1 1}$ & 186.8 & 189.6 & 195.0 & 173.7 & 192.6 & 188.9 & 192.6 & 192.6 \\
$\mathbf{2 0 1 2}$ & 200.0 & 200.5 & 206.4 & 184.1 & 203.2 & 202.6 & 203.2 & 203.2 \\
$\mathbf{2 0 1 3}$ & 209.7 & 213.3 & 220.2 & 196.0 & 217.9 & 210.4 & 217.9 & 217.9 \\
\hline Diff $\mathbf{2 0 1 3 - 2 0 0 1}$ & 109.7 & 113.3 & 120.2 & 96.0 & 117.9 & 110.4 & 117.9 & 117.9 \\
\hline AAGR & 6.4 & 6.5 & 6.8 & 5.8 & 6.7 & 6.4 & 6.7 & 6.7 \\
\hline
\end{tabular}


lower. For high SES schools on the other hand, the increase was very similar to the increase associated with the secondary education price index for Victoria.

From Table 7 we note that there appears to be a fall in the quality in the low SES schools since from Table 7 the quality adjusted index difference from 2001 to 2013 was estimated as 117.9 percent compared with 95.5 percent in the baseline index from Table 3 . This implies that the quality in these schools has decreased since by explicitly modelling the quality changes our price index jumps by so much. As can be noted from Table A.1, the number of VCE subjects offered is one example of a substantial difference in school characteristics between low SES schools and other private schools in Victoria. This is consistent with the finding in Perry and Southwell (2014) that students attending low SES schools may not have access to the same academic curriculum as other schools. Ryan and Watson (2010) conclude that the increases in Government funding to private schools has primarily been used to improve the quality of the learning experiences of students. Thus, even though Government funding already constitutes a significant proportion of the recurrent funding for low SES schools, their quality appears to have decreased. Research by Patrinos (2013) finds that those students from low SES backgrounds in the Netherlands are helped the most by a private school education which would imply that the return on this investment may indeed be higher. Thus one might conclude that government funding for low SES schools is needed at even a higher level than is currently received.

\section{Conclusions}

Tuition fees are the most significant expenditure for parents of the $40 \%$ of all secondary school aged children attending private schools in Victoria, Australia. The recent rapid rise in these costs has become a primary concern for these parents. Using a unique panel data set of private school characteristics and tuition we derive a series of price indices by subgroups of these schools. 
A set of baseline price indices were constructed by estimating a hedonic model that included school and year fixed effects. These indices indicate that the annual growth rate for these schools is similar to tuition fee increases in other countries and that the pricing changes differ by schools type. We detected a procyclical pattern in the price changes for some schools that indicated that their fees rose faster during expansions and slower during downturns.

We also determined a set of quality-adjusted price indices by the inclusion of timevarying attributes for each school. The characteristics that appear to have a positive impact on fees vary by type of school. Overall we find a positive influence for the number of subject and cocurricular offerings, with mixed results for certain types of schools. The growth rates from these indices indicated that metropolitan, systemic Catholic and middle $S E S$ schools appear to match the growth rate measured by the Australian Bureau of Statistics' secondary school CPI for Victoria. However, for low SES schools we found price increases that were substantially different from that indicated by the baseline index. While at the same time, enrolments have been growing in this group of schools. However, since tuition fees at low SES schools are highly responsive to the business cycle and have remained fairly affordable over the sample period, this suggests that these schools are restricted in their ability to raise tuition fees and may need to rely on more government funding. 


\section{References}

Australian Bureau of Statistics, (2007), Household Income and Income Distribution, Australia, 2005-2006, Document \#6523.0., Canberra, ACT.

Australian Bureau of Statistics, (2011), Consumer Price Index: Concepts, Sources and Methods 2011, Document \#6461.0., Canberra, ACT.

Australian Bureau of Statistics, (2012), Census of Population and Housing: Time Series Profile DataPack, 2011 Third Release, Document \# 2069.0.30.003, Canberra, ACT.

Australian Curriculum, Assessment, and Reporting Authority, (2013), National Report on Schooling in Australia 2011, ACARA, Sydney.

Baumol, W., (1996), "Children of performing arts, the economic dilemma: The climbing costs of health care and education", Journal of Cultural Education, 20, pp. 183-206.

Caldwell, B. J.,(2010), "Is Private Schooling Becoming the Preferred Model of Choice in Australia?", Journal of School Choice, 4, pp 378-397.

Chwelos, P., (2003), “Approaches to performance measurement in hedonic analysis: Price indexes for laptop computers in the 1990s", Economics of Innovation and New Technology, 12, pp. 199-224.

Court, A. T., (1939), "Hedonic price indexes with automotive examples, in: The dynamics of automobile demand", The General Motors Corporation, New York pp. 99-117.

Dellas, H. and P. Sakellaris, (2003), "On the cyclicality of schooling: Theory and evidence", Oxford Economic Papers, 55, 148-72.

Dynarski, S., J. Gruber, and D. Li, (2009), "Cheaper by the dozen: Using sibling discounts at Catholic schools to estimate the price elasticity of private school attendance", NBER working paper \#15461, National Bureau of Economic Research, Cambridge, MA.

Fernandez-Cornejo, J. and S. Jans, (1995), "Quality-adjusted price and quantity indices for pesticides", American Journal of Agricultural Economics, 77, pp. 645-659.

Fraser, A. and M. Nadin, (2014), "Parents prepared to pay as private school fees lift 5pc", The Australian, Jan 11.

Gonski, D., K. Boston, K. Greiner, C. Lawrence, B. Scales, and P. Tannock (2011), Review of Funding for Schooling - Final Report December 2011, downloaded www.schoolfunding.gov.au, $25^{\text {th }}$ August 2014.

Griliches, Z., (1961), Hedonic price indexes for automobiles: An econometric analysis of quality change, in The Price Statistics of the Federal Government, General series no. 73, Columbia University Press, New York, pp. 137-196.

Hashimoto, K. and J. A Heath, (1995), "Income Elasticities of Educational Expenditure by Income Class: The case of Japanese Households", Economics of Education Review, 14, 63-71. 
Hodrick, R. and E. Prescott (1997), "Postwar US Business Cycles: An Empirical Investigation", Journal of Money, Credit and Banking, 29, pp. 1-16.

Karikari, J. and H. Dezhbakhsh, (2013), "Are selective private and public colleges affordable?”, Education Economics, 21, 60-78.

Marshall, K., C. Butt, and B. Preiss, (2013), "Fees set to soar as schools compete", The Age, November 17, News pp. 3.

Messer, D. and S. Wolter, (2010), "Time-to-degree and the business cycle", Education Economics, 18, 111-123.

OECD,,(2003), Education at a Glance 2002: OECD Indicators, OECD Publishing, Paris. DOI: http://dx.doi.org/10.1787/eag-2003-en

OECD, (2014), Education at a Glance 2013: OECD Indicators, OECD Publishing, Paris. DOI: http://dx.doi.org/10.1787/eag-2013-en

Patrinos, H., (2013), "Private education provision and public finance: the Netherlands", Education Economics, 21, 392-414.

Perry, L. B., (2012), "What do we know about the causes and effects of school socioeconomic composition? A review of the literature", Education and Society, 30(1), 19-35.

Perry, L. B. and L. Southwell, (2014), “Access to academic curriculum in Australian secondary schools: a case study of a highly marketised education system", Journal of Education Policy, 29, pp. 467-485.

Rosen, S., (1974), Hedonic prices and implicit markets: Product differentiation in pure competition, Journal of Political Economy, 82, 34-55.

Ryan, C. and L. Watson (2010), "Choosers and Losers: The impact of government subsidies on Australian secondary schools", Australian Journal of Education, 54, 86-107.

Schwartz, A. E. and B. Scafidi, (2004), "What's happened to the price of college? Quality-Adjusted Net Price Indexes for Four-Year Colleges." The Journal of Human Resources, 39, pp. 723-745.

The Good Schools Guide: Victoria 2001-2013, (2001-2013) Hobsons Australia, Melbourne.

Van Dalen, J. and B. Bode, (2004), "Quality-corrected price indices: the case of the Dutch new passenger car market, 1990-1999”, Applied Economics, 36, pp. 1169-1197. 


\section{Appendix A.}

Table A.1 Explanatory Variable Means by Selected Year

\begin{tabular}{|c|c|c|c|c|c|c|c|c|c|c|c|}
\hline & & 2001 & 2005 & 2009 & 2013 & & & 2001 & 2005 & 2009 & 2013 \\
\hline Number & All & 3 & 2 & 2 & 2 & $\%$ Students Uni & All & 79 & 75 & 75 & 76 \\
\hline Language & Systemic & 2 & 2 & 2 & 2 & & Systemic & 70 & 65 & 64 & 68 \\
\hline \multirow[t]{5}{*}{ Options } & Metro & 3 & 2 & 3 & 3 & & Metro & 81 & 77 & 77 & 78 \\
\hline & Regional & 2 & 2 & 2 & 2 & & Regional & 74 & 71 & 70 & 72 \\
\hline & Low & 2 & 1 & 1 & 1 & & Low & 71 & 64 & 69 & 72 \\
\hline & Middle & 2 & 2 & 2 & 2 & & Middle & 84 & 83 & 83 & 83 \\
\hline & High & 4 & 3 & 4 & 3 & & High & 91 & 93 & 90 & 91 \\
\hline Number & All & 10 & 11 & 11 & 12 & Number VCE & All & 28 & 35 & 37 & 39 \\
\hline Music & Systemic & 9 & 11 & 11 & 11 & Subjects & Systemic & 29 & 37 & 43 & 45 \\
\hline \multirow[t]{5}{*}{ Options } & Metro & 10 & 11 & 11 & 12 & & Metro & 28 & 35 & 38 & 39 \\
\hline & Regional & 10 & 10 & 10 & 11 & & Regional & 26 & 33 & 36 & 38 \\
\hline & Low & 6 & 7 & 8 & 7 & & Low & 20 & 24 & 22 & 24 \\
\hline & Middle & 11 & 11 & 12 & 13 & & Middle & 26 & 33 & 36 & 37 \\
\hline & High & 12 & 13 & 13 & 14 & & High & 29 & 36 & 38 & 39 \\
\hline Number & All & 15 & 17 & 18 & 21 & Enrolments & All & 505 & 492 & 649 & 746 \\
\hline Sport & Systemic & 13 & 16 & 18 & 21 & & Systemic & 939 & 928 & 1015 & 1066 \\
\hline \multirow[t]{5}{*}{ Options } & Metro & 15 & 18 & 19 & 23 & & Metro & 985 & 974 & 1051 & 1076 \\
\hline & Regional & 15 & 16 & 17 & 18 & & Regional & 785 & 724 & 883 & 939 \\
\hline & Low & 10 & 11 & 11 & 12 & & Low & 505 & 492 & 649 & 746 \\
\hline & Middle & 17 & 19 & 20 & 23 & & Middle & 921 & 1063 & 1112 & 1113 \\
\hline & High & 20 & 22 & 22 & 29 & & High & 1134 & 997 & 1145 & 1132 \\
\hline Number & All & 15 & 17 & 17 & 32 & Federal Funds & All & 2876 & 4137 & 5115 & 6352 \\
\hline Other & Systemic & 14 & 17 & 18 & 33 & & Systemic & 3904 & 5117 & 6370 & 7473 \\
\hline \multirow[t]{5}{*}{ Co-curricular } & Metro & 15 & 17 & 18 & 35 & & Metro & 2691 & 3955 & 4794 & 6033 \\
\hline & Regional & 14 & 16 & 16 & 25 & & Regional & 3453 & 4639 & 5999 & 7223 \\
\hline & Low & 10 & 12 & 12 & 20 & & Low & 3731 & 4548 & 6000 & 7779 \\
\hline & Middle & 14 & 17 & 18 & 32 & & Middle & 2270 & 3754 & 4500 & 5923 \\
\hline & High & 19 & 20 & 21 & 42 & & High & 1200 & 2172 & 2494 & 3373 \\
\hline$\%$ Study scores & All & 13 & 12 & 12 & 11 & State Funds & All & 906 & 1059 & 1410 & 1733 \\
\hline \multirow[t]{6}{*}{$40+$} & Systemic & 8 & 8 & 8 & 8 & & Systemic & 1101 & 1277 & 1742 & 2197 \\
\hline & Metro & 14 & 13 & 13 & 13 & & Metro & 833 & 989 & 1330 & 1657 \\
\hline & Regional & 10 & 10 & 10 & 8 & & Regional & 1129 & 1247 & 1631 & 1941 \\
\hline & Low & 12 & 9 & 9 & 8 & & Low & 1436 & 1566 & 1993 & 2440 \\
\hline & Middle & 13 & 13 & 12 & 12 & & Middle & 790 & 827 & 1042 & 1211 \\
\hline & High & 23 & 22 & 23 & 22 & & High & 415 & 506 & 704 & 812 \\
\hline
\end{tabular}


Table A.2: $F$ Statistics by specification for baseline model specifications.

\begin{tabular}{l|llc}
\hline Coefficients Tested & \multicolumn{3}{|c}{ Specification } \\
\hline School Fixed Effects $\beta_{2} \ldots, \beta_{J}=0$ & $3697.9^{* * *} \dagger$ & $3791.8^{* * *}$ & (3) \\
Year Fixed Effects $\rho_{1} \ldots, \rho_{T}=0$ & $239.0^{* * *}$ & $72.0^{* * *}$ & $141.7^{* * * *}$ \\
Metropolitan*Year Fixed Effects $\delta_{1} \ldots, \delta_{T}=0$ & & 1.6 & \\
High $S E S^{*}$ Year Fixed Effects $\pi_{1} \ldots, \pi_{T}=0$ & & & 1.5 \\
Low $S E S^{*}$ Year Fixed Effects $\theta_{1} \ldots, \theta_{T}=0$ & & & 1.3 \\
Systemic Catholic*Year Fixed Effects $\lambda_{1} \ldots, \lambda_{T}=0$ & & & 0.3 \\
\hline
\end{tabular}

$\dagger$ The significance levels $\left(*\right.$ for $.1, * *$ for .05 , and ${ }^{* * *}$ for .01$)$ are based on standard errors clustered by school except the test of the school fixed effects $\left(\beta_{2} \ldots, \beta_{J}=0\right)$ which was conducted with the usual robust (White/Huber) covariance to avoid misspecification.

Table A.3: F-Statistics by specification for quality-adjusted model specifications.

\begin{tabular}{l|ccc}
\hline & \multicolumn{3}{|c}{ Specification } \\
Coefficients Tested & (1) & (2) \\
\hline School Fixed Effects $\beta_{2} \ldots, \beta_{J}=0$ & $947.6^{* * *+}$ & $779.1^{* * *}$ & $173.3^{* * *}$ \\
Time-Varying School Characteristics $\gamma_{1} \ldots, \gamma_{K}=0$ & $2.0^{* *}$ & $2.0^{* *}$ & 0.8 \\
Year Fixed Effects $\rho_{1} \ldots, \rho_{T}=0$ & $62.9^{* * *}$ & $22.6^{* * *}$ & $57.7^{* * *}$ \\
Metropolitan*Time-Varying School Characteristics $\tau_{1} \ldots, \tau_{K}=0$ & & 0.8 & \\
Metropolitan $*$ Year Fixed Effects $\delta_{1} \ldots, \delta_{T}=0$ & & 1.4 & \\
High $S E S^{*}$ Time-Varying School Characteristics $\psi_{1} \ldots, \psi_{K}=0$ & & & 0.7 \\
Low $S E S^{*}$ Time-Varying School Characteristics $\xi_{1} \ldots, \xi_{K}=0$ & & & $3.2^{* * *}$ \\
Systemic Catholic*Time-Varying School Characteristics & & & 1.2 \\
$v_{1} \ldots, v_{K}=0$ & & & $2.0^{* *}$ \\
High $S E S^{*}$ Year Fixed Effects $\pi_{1} \ldots, \pi_{T}=0$ & & & 0.9 \\
Low $S E S^{*}$ Year Fixed Effects $\theta_{1} \ldots, \theta_{T}=0$ & & & 0.4 \\
Systemic Catholic*Year Fixed Effects $\lambda_{1} \ldots, \lambda_{T}=0$ & & & \\
\hline
\end{tabular}

$\$$ The significance levels $\left(*\right.$ for $.1,{ }^{* *}$ for .05 , and ${ }^{* * *}$ for .01$)$ are based on standard errors clustered by school except the test of the school fixed effects $\left(\beta_{2} \ldots, \beta_{J}=0\right)$ which was conducted with the usual robust (White/Huber) covariance to avoid misspecification. 


\section{University Library}

\section{- M M N E R VA A gateway to Melbourne's research publications}

Minerva Access is the Institutional Repository of The University of Melbourne

Author/s:

Hirschberg, J;Lye, J

Title:

Secondary School Fee Inflation: An Analysis of Private High Schools in Victoria, Australia

Date:

2017

Citation:

Hirschberg, J. \& Lye, J. (2017). Secondary School Fee Inflation: An Analysis of Private High Schools in Victoria, Australia. Education Economics, 25 (5), pp.482-500. https:// doi.org/10.1080/09645292.2017.1295024.

Persistent Link:

http://hdl.handle.net/11343/295961 